\title{
Extra-adrenal paraganglioma of the prostate
}

\author{
Hong-Hau Wang, MD, Yen-Lin Chen, MD, ${ }^{*+} H a o-L u n$ Kao, MD; ${ }^{*}$ Shih-Chung Lin, MD; ${ }^{;}$Chiao-Hua Lee, MD,* \\ Guo-Shu Huang, MD; ${ }^{*}$ Wei-Chou Chang, MD*
}

*Department of Radiology, Tri-Service General Hospital, National Defense Medical Center, Taipei, Taiwan, Republic of China; 'Department of Radiology, Armed-Forces Taoyuan General Hospital, Taoyuan,
Taiwan, Republic of China; ${ }^{\circledR}$ Department of Pathology, Tri-Service General Hospital, National Defense Medical Center, Taipei, Taiwan, Republic of China

Cite as: Can Urol Assoc J 2013;7(5-6):e370-2. http://dx.doi.org/10.5489/cuaj.1221

Published online May 13, 2013.

\section{Abstract}

Extra-adrenal pheochromocytomas, or paragangliomas, are rare tumours that may develop from extra-adrenal chromaffin cells, and most occur in the organ of Zuckerkandl. Extra-adrenal paraganglioma of the prostate is extremely rare. We report a 53-year-old man with hypertension and lower urinary tract symptoms, who was initially diagnosed with benign prostate hyperplasia. Computed tomography $(\mathrm{CT})$ showed a large heterogenously enhancing mass in the prostate, imprinting the right distal ureter and urinary bladder. Before surgical intervention, CT-guided biopsy of the prostatic mass was performed and the result of histologic examination confirmed extra-adrenal paraganglioma. He underwent radical prostatectomy, partial cystectomy and right ureteroneocystostomy. The patient recovered and his blood pressure returned within normal range after surgical removal of the prostate tumour. In this article, we stress that the rarity of prostatic paraganglioma, preoperative localization and imaging-guided biopsy were useful in determining the surgical strategy.

\section{Introduction}

Extra-adrenal phenochromocytomas are catecholamine-producing tumours that may arise from any site where chromaffin tissue is present. They are most frequently found in the organ of Zuckerkandl (around the root of the inferior mesenteric artery), but it also may be uncovered in other locations, such as retroperitoneum and the urinary bladder. Paragangliomas occurring in the prostate are extremely rare. Clinical presentations are not specific and the classic triad of symptoms (i.e., episodic headache, sweating, and tachycardia) are not common. Therefore, the diagnosis is usually delayed. In reviewing the English literature, we found only 7 cases which were preoperatively diagnosed as prostate paragangliomas. ${ }^{1-9}$ We report an unusual case of a prostatic paraganglioma diagnosed with computed tomography
(CT)-guided biopsy, and successfully removed by surgical intervention. We also review related articles with preoperative diagnosis of this rare entity.

\section{Case report}

A 53-year-old man with a half-year history of hypertension presented to our clinic because he had difficulty in starting a urine stream, weak flow and dribbling after urination for 1 month. His hypertension was paroxysmal and was well-controlled with anti-hypertension drugs followed at local medical clinics. He was otherwise well, and had no headaches, palpitations, anxiety, flushing, diaphoresis or weight loss.

At digital rectal examination, an enlargement of the prostate was palpable. There were no abnormalities on basic blood tests, and his age-adjusted prostate-specific antigen (PSA) level was normal. Ultrasonography of abdomen revealed asymmetrical enlargement of the prostate. Contrast enhanced CT of abdomen and pelvis showed one large, heterogeneously-enhanced mass in the prostate, imprinting the bladder base and right ureterovesical junction, without clear demarcation from the prostate (Fig. 1). No other visceral abnormality was seen. On cystoscopy, a prominence about a few centimeters in diameter was noted at the level of the bladder neck. The bladder and lower prostatic urethra were normal.

For further investigation, a CT-guided trans-gluteal biopsy of the prostatic mass, rather than the transrectal ultrasound (TRUS) guided biopsy, was performed since the patient had a history of recent rectal bleeding. A series of 6 prostate biopsies were taken. Histologic examination of the specimen showed normal prostatic tissue infiltrated by nests and cords of tumour cells separated by sparse connective tissue. The tumour cells were large, polygonal, relatively uniform and with abundant highly granular and eosinophilic cytoplasm (Fig. 2). Immunohistochemically, the tumour cells were negative for PSA and positive for chromogranins (Fig. 2, inset), synaptophysin, neurofilament, neuron-specific enolase and 


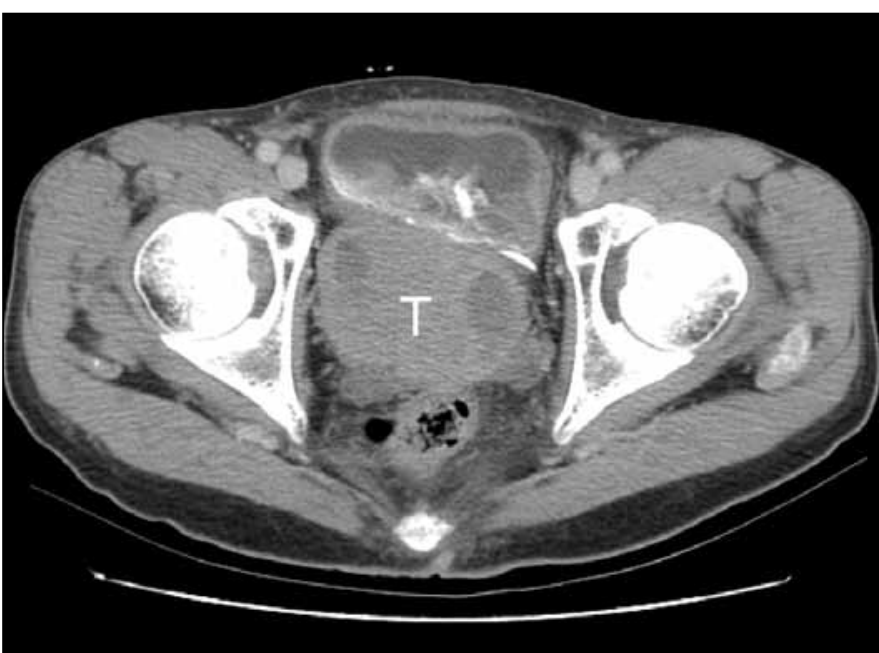

Fig. 1. Contrast-enhanced computed tomography of pelvis showed one heterogeneously-enhanced mass $(\mathrm{T})$ in the prostate, compressing the right bladder base at ureterovesical junction, without clear demarcation from the prostate.

S-100 protein. These results confirmed a paraganglioma of the prostate.

The patient was examined by an iodine-123 metaiodobenzylguanidine scintigraphy with increased radiotracer uptake in the corresponding prostatic mass on CT imaging. No evidence of other abnormal uptake was found. The 24-hour urinary norepinephrine and epinephrine level were increased, but the dopamine level was within the normal range.

Following the diagnosis of extra-adrenal paraganglioma,

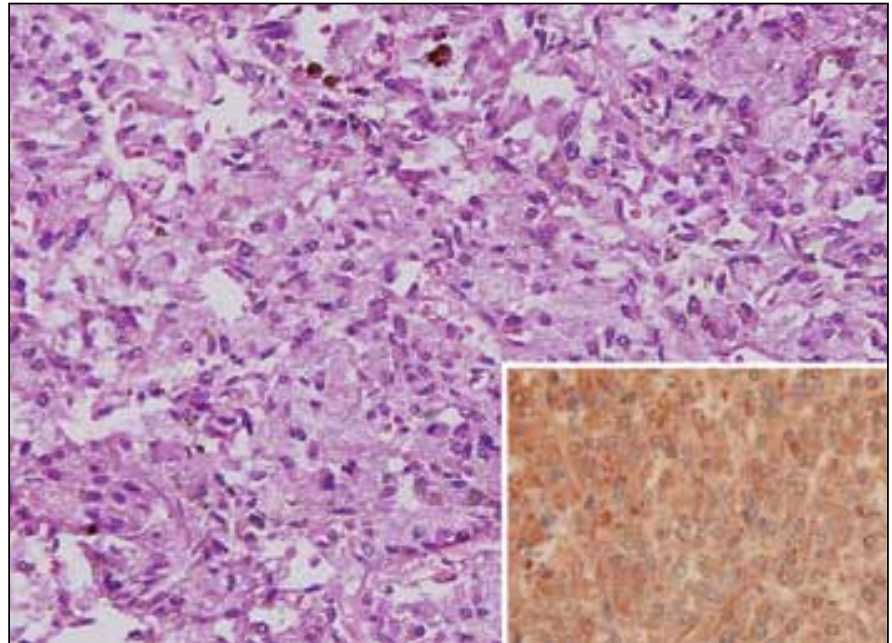

Fig. 2. Photomicrograph of prostatic tumour biopsy specimen showed the tumour cells were large, polygonal, relatively uniform and with abundant highly granular and eosinophilic cytoplasm separated by connective tissue septa (hematoxylin and eosin $\times 200$ ). Immunostaining for chromogranin showed diffuse cytoplasmic reactivity (inset).

a precautional treatment with prazosin was given before surgery. Exploratory laparotomy with radical prostatectomy, partial cystectomy and right ureteroneocystostomy were performed. Intraoperatively, his blood pressure slightly increased (peak blood pressure 150/90 $\mathrm{mmHg}$ ) and he reacted with tachycardia during manipulation of the tumour. Pelvic lymph node dissection was negative for malignancy.

The blood pressure stabilized within the normal range after prostatectomy. The postoperative period was unevent-

\begin{tabular}{|c|c|c|c|c|c|c|c|c|}
\hline Authors & $\begin{array}{l}\text { Age, } \\
\text { year }\end{array}$ & Initial presentations & DRE & Functional & $\begin{array}{l}\text { Diagnostic } \\
\text { modality }\end{array}$ & $\begin{array}{c}\text { LN } \\
\text { Metastasis }\end{array}$ & Malignancy & Surgical intervention \\
\hline Mehta et al. ${ }^{1}$ & 29 & $\begin{array}{c}\text { Edema of the right } \\
\text { leg }\end{array}$ & Yes & No & $\begin{array}{l}\text { Sono- } \\
\text { guided } \\
\text { biopsy }\end{array}$ & Yes & Malignant & $\begin{array}{l}\text { Unresectable at surgical } \\
\text { exploration }\end{array}$ \\
\hline Shapiro et al. ${ }^{5}$ & 17 & $\begin{array}{c}\text { Painless } \\
\text { hematuria with } \\
\text { hydronephrosis of } \\
\text { left kidney }\end{array}$ & Yes & No & $\begin{array}{l}\text { Sono- } \\
\text { guided } \\
\text { biopsy }\end{array}$ & Yes & Malignant & $\begin{array}{l}\text { Unresectable at surgical } \\
\text { exploration }\end{array}$ \\
\hline Hasselager et al. ${ }^{6}$ & 29 & Hematuria & No & No & $\begin{array}{l}\text { Cystoscopy } \\
\text { with biopsy }\end{array}$ & No & Benign & $\begin{array}{c}\text { Radical TUR of the } \\
\text { tumour }\end{array}$ \\
\hline Parwani et al. ${ }^{7}$ & 35 & Hematuria & No & No & $\begin{array}{l}\text { Sono- } \\
\text { guided } \\
\text { biopsy }\end{array}$ & No & Benign & NA \\
\hline Perlmutter et al. ${ }^{8}$ & 63 & Hypertension & Yes & Yes & $\begin{array}{l}\text { Sono- } \\
\text { guided } \\
\text { biopsy }\end{array}$ & No & Benign & Resection of tumour \\
\hline Campodonico et al. ${ }^{9}$ & 33 & Epigastralgia & Yes & No & $\begin{array}{l}\text { Sono- } \\
\text { guided } \\
\text { biopsy }\end{array}$ & No & Benign & Radical prostatectomy \\
\hline Our patient & 53 & $\begin{array}{l}\text { Hypertension with } \\
\text { LUTS }\end{array}$ & Yes & Yes & $\begin{array}{l}\text { CT-guided } \\
\text { biopsy }\end{array}$ & No & Benign & Radical prostatectomy \\
\hline
\end{tabular}


Wang et al.

ful. At the 1-year follow-up visit, there was no evidence of recurrent disease.

\section{Discussion}

Extra-adrenal pheochromocytomas, so-called paragangliomas are rare neuroendocrine tumours with devastating potential, and have been described anywhere along the abdominal sympathetic chain, thoracic cavity, cervical region and bladder. Within these locations, prostatic paraganglioma is exceptionally rare. First described by Mehta and colleagues in 1979, ${ }^{1}$ fewer than 10 cases have been reported in the past 30 years, and, including our patient, only 7 reported cases in the English literature have had preoperative tissue diagnosis since then (Table 1).

The clinical presentation of prostatic paragangliomas is highly variable, largely depending on the functional status of the tumour. If the tumour is functional, the patient may experience symptoms and signs of catecholamine overproduction, such as hypertension, headaches, palpitations, sweating, tachycardia and anxiety, and may be precipitated by micturition. In non-functional tumours, the initial presentations were hematuria, obstructive symptoms and a palpable mass in the prostate..$^{1,5,9}$ The laboratory diagnosis is made by detecting an elevation of the 24-hour urinary total catacholamine and vanillylmandelic acid levels, but can only be used in functional paragangliomas. ${ }^{2-4,8}$ The diagnosis of non-functional paraganglioma may not be made until an advanced stage due to asymptomatic presentation or nonspecific symptoms. In the reported 5 cases of non-functional prostatic paraganglioma, 2 were unresectable at surgical exploration. ${ }^{1,5}$ Thus, a timely tissue diagnosis is important.

The distinction of malignant or benign represents the crucial point, but remains a diagnostic challenge. Clinical parameters proposed to predict malignancy include higher urinary dopamine and vanillylmandelic acid levels, an extra-adrenal tumour location, greater tumour weight, and postoperative persistent hypertension. ${ }^{10}$ Histopathological studies have shown that confluent tumoural necrosis, vascular invasion, capsular invasion and greater mitotic activity indicate malignancy. However, such grading systems require assessment of many variables and, to date, have not been applied prospectively for diagnostic or prognostic purposes. The presence of metastases at non-chromaffin sites provides the only currently widely accepted means to define malignant paraganglioma. In our patient, the diagnosis of benign paraganglioma was therefore made based on the absence of the metastatic lesion.

Paraganglioma involving the prostate may be misdiagnosed as prostate carcinoma. Due to the unusual location and the histologic feature, high-grade adenocarcinoma of prostate should be considered in the differential diagno- sis. In this case, immunostains for PSAS, prostate-specific acid phosphatase, cytokeratin 7, cytokeratin 20 were negative, while those for chromogranin and synaptophysin were strongly positive - these factors helped in the diagnosis.

The definitive and most effective treatment for prostatic paraganglioma is radical operation. ${ }^{1,6-9}$ Other treatment options for extra-adrenal paraganglioma include chemotherapy, as well as radiotherapy. The latter is usually used for palliative relief of symptoms associated with bone metastasis.

\section{Conclusion}

This case illustrates a rare condition of prostatic paraganglioma. As yet, the prognosis of prostatic paraganglioma has not been clearly defined owing to the absence of reliable parameters and the small number of reported cases. Long-term follow-up with regular examinations of catecholamine production, cross-sectional CT imaging for anatomical evaluation, and iodine-123 metaiodobenzylguanidine scintigraphy for functional evaluation are therefore essential.

Competing interests: None declared.

This paper has been peer-reviewed.

\section{References}

1. Mehta M, Nadel NS, Lonni Y, et al. Malignant paraganglioma of the prostate and retroperitoneum. J Urol 1979:121:376-8.

2. Nielsen VM, Skovgaard N, Kvist N. Phaeochromocytoma of the prostate. Br J Urol 1987;59:478-9. http://dx.doi.org/10.1111/i.1464-410X.1987.tb04851.x

3. Dennis PJ, Lewandowski AE, Rohner TJ Jr, et al. Pheochromocytoma of the prostate: an unusual location. J Urol 1989;141:130-2.

4. Voges GE, Wippermann F, Duber C, et al. Pheochromocytoma in the pediatric age group: the prostate-an unusual location. J Urol 1990;144:1219-21.

5. Shapiro B, Gonzalez E, Weissman A, et al. Malignant paraganglioma of the prostate: case report, depiction by meta-iodobenzylguanidine scintigraphy and review of the literature. Q J Nucl Med 1997:41:36-41.

6. Hasselager T, Horn T, Rasmussen F. Paraganglioma of the prostate. A case report and review of the literature. Scand J Urol Nephrol 1997;31:501-3. http://dx.doi.org/10.3109/00365599709030651

7. Parwani AV, Cao D, Epstein Jl. Pathologic quiz case: a 35-year-old man with hematuria. Paraganglioma involving the prostate. Arch Pathol Lab Med 2004;128:e104-6.

8. Perlmutter AE, Livengood R, Zaslau S, et al. Periprostatic pheochromocytoma. Urology 2005;66:194. http://dx.doi.org/10.1016/i.urology.2005.01.012

9. Campodonico F, Bandelloni R, Maffezzini M. Paraganglioma of the prostate in a young adult. Urology 2005;66:657. http://dx.doi.org/10.1016/i.urology.2005.03.001

10. John H, Ziegler WH, Hauri D, et al. Pheochromocytomas: can malignant potential be predicted? Urology 1999;53:679-83. http://dx.doi.org/10.1016/S0090-4295(98)00612-8

Correspondence: Dr. Wei-Chou Chang, Department of Radiology, Tri-Service General Hospital, 325, Cheng-Kung Road, Sec. 2, Taipei, 114, Taiwan, Republic of China; fax: +886-2-8792-7245; weichou.chang@gmail.com 